\title{
Energy Analysis Method Based on Wavelet Transform for Sensor Fault Diagnosis
}

\author{
Pengpeng Qian 2, 1, a , Jinguo Liu ${ }^{1,2, b}$, Wei Zhang ${ }^{1, c}$, Yingzi Wei ${ }^{2}$ \\ ${ }^{1}$ Center for Space Automation Technologies \& Systems, State Key Laboratory of Robotics, \\ Shenyang Institute of Automation, Chinese Academy of Sciences, Shenyang 110016, China; \\ ${ }^{2}$ School of Information Science \& Engineering, Shenyang Ligong University, Shenyang 110004 , \\ China; \\ aqianpengpeng@sia.cn , lilujinguo@sia.cn, 'czhangwei@sia.cn
}

Keywords: Wavelet Analysis, Sensor Faults, Fault Diagnosis, Energy Analysis

\begin{abstract}
Wavelet analysis with its unique features is very suitable for analyzing non-stationary signal, and it can also be used as an ideal tool for signal processing in fault diagnosis. The characteristics of the faults and the necessary information on the diagnosis can be constructed and extracted respectively by wavelet analysis. Though wavelet analysis is specialized in characteristics extraction, it can not determine the fault type. So this paper has proposed an energy analysis method based on wavelet transform. Experiment results show the method is very effective for sensor fault diagnosis, because it can not only detect the sensor faults, but also determine the fault type.
\end{abstract}

\section{Introduction}

With the development of automation technology and the increase of large-scale automation projects, sensors used for state monitor and parameter measurement have become more and more important. And the sensor faults are inevitable, because the sensor usually works in bad environment. Once the sensor faults occur, it will lead to the degradation of automation system's performance, and even disastrous consequences. According to statistics, accidents due to sensor faults account for $60 \%$ in the industrial production [1]. In 1980s, a pressure sensor fault led to an explosion during a ground experiment of NASA [2]. In short, the sensor fault diagnosis is significant and practical.

The existing sensor fault diagnosis methods include hardware redundancy [3], analytical redundancy [4], neural network method [5], model-based LES method [6], and wavelet analysis [7]. Among them, wavelet analysis not only overcomes the defects of Fourier transform without localization in the time domain, but also makes up the shortage of the short time Fourier transform in fixed resolution. What's more, with the characteristics of multi-resolution analysis, it can analyze signals both globally and locally.

Though wavelet analysis is an ideal tool for sensor fault detection, it can not determine the fault type. So this paper has proposed an energy analysis method based on wavelet transform.

\section{The Basis of Wavelet Analysis}

\subsection{The Essence and Process of Wavelet Analysis.}

The essence of wavelet analysis is that a signal is decomposed into a series of superimposed wavelet functions, which are called wavelet basis functions formed by translation and scale expansion of a mother wavelet function.

The process of wavelet analysis is as follows.

Step 1. Select a mother wavelet function $\varphi(t)$; 
Step 2. Get wavelet basis functions $\varphi_{a, b}(t)$ by translation and scale expansion of $\varphi(t)$. And a is the expansion factor, $b$ is the translation factor.

$$
\varphi_{a, b}(t)=\frac{1}{\sqrt{a}} \varphi\left(\frac{t-b}{a}\right), a, b \in R ; a>0
$$

Step 3. Get the coefficients of wavelet transform $\mathrm{WT}_{\mathrm{f}}(\mathrm{a}, \mathrm{b})$ by convolution between $\mathrm{f}(\mathrm{t})$ and $\varphi_{\mathrm{a}, \mathrm{b}}(\mathrm{t})$.

\subsection{The Type of Wavelet Analysis}

(1) Continuous Wavelet Transform

In step 2, if $\mathrm{a}$ and $\mathrm{b}$ are both chosen as continuous values, $\varphi_{\mathrm{a}, \mathrm{b}}(\mathrm{t})$ is called continuous wavelet basis functions. Analyzing a function in $\mathrm{L}^{2}(\mathrm{R})$ space with $\varphi_{\mathrm{a}, \mathrm{b}}(\mathrm{t})$ is called continuous wavelet transform $(\mathrm{CWT})$, which is expressed as $\left(\varphi_{\mathrm{a}, \mathrm{b}} *(\mathrm{t})\right.$ is the complex conjugate of $\varphi_{\mathrm{a}, \mathrm{b}}(\mathrm{t})$, similarly hereinafter):

$$
\mathrm{WT}_{\mathrm{f}}(\mathrm{a}, \mathrm{b})=<\mathrm{f}(\mathrm{t}), \varphi_{\mathrm{a}, \mathrm{b}}(\mathrm{t})>=\frac{1}{\sqrt{\mathrm{a}}} \int_{\mathrm{R}} \mathrm{f}(\mathrm{t}) \varphi^{*}\left(\frac{\mathrm{t}-\mathrm{b}}{\mathrm{a}}\right) \mathrm{dt}
$$

\section{(2) Discrete Wavelet Transform}

In step 2, if $\mathrm{a}$ and $\mathrm{b}$ are both chosen as discrete values, $\varphi_{\mathrm{a}, \mathrm{b}}(\mathrm{t})$ is called discrete wavelet basis functions. And it is rewritten as:

$$
a_{0}^{-\frac{j}{2}} \varphi\left[a_{0}^{-j}\left(t-k a_{0}^{j} b_{0}\right)\right]=a_{0}^{-\frac{j}{2}} \varphi\left[a_{0}^{-j} t-k b_{0}\right]
$$

It is denoted as $\varphi_{a_{0}^{j}, k b}(t)$, analyzing a function in $L^{2}(R)$ space with such wavelet basis functions can be called discrete wavelet transform (DWT), which is expressed as:

$$
\mathrm{WT}_{\mathrm{f}}(\mathrm{a}, \mathrm{b})=<\mathrm{f}(\mathrm{t}), \varphi_{\mathrm{a}_{0}{ }^{\mathrm{j}}, \mathrm{kb}_{0}}>=\int \mathrm{f}(\mathrm{t}) \varphi_{\mathrm{a}_{0}^{\mathrm{j}}, \mathrm{kb}_{0}} *(\mathrm{t}) \mathrm{dt} \quad \mathrm{j}=0,1,2, \cdots, \mathrm{k}, \mathrm{k} \in \mathrm{z}
$$

Discrete wavelet transform is a "multi-resolution analysis" process. It commonly uses "Mallat algorithm [8]" for fast computation.

\section{Sensor Faults' Classification and Diagnostic Characteristics}

\subsection{Sensor Faults' Classification.}

Sensor faults are caused by many factors, and the fault types are various. Based on the extent of the faults, they are divided into hard fault and soft fault. Hard fault is the fault caused by structural damage, and soft fault is the fault caused by the change of sensor characteristics. According to the performance of the faults, they can be divided into intermittent fault and permanent fault. According to the causes of the faults, they can be divided into bias fault, impact fault, open-circuit fault, short-circuit fault, drift fault, periodic fault and random fault [9].

\subsection{Sensor Faults' Diagnostic Process and Characteristics}

(1) The signal is analyzed with db6 wavelet for three layers;

(2) According to the set threshold, analyze the 3rd layer low-frequency signal to find the mutant point where fault starts. If the mutant point is not found, it indicates there is no fault or the fault is periodic fault. Then analyze the 1st layer low-frequency signal, the fault is periodic fault when the mutant point is found, or there is no fault. 
(3) Suppose $\mathrm{f}=|\mathrm{a} 3-\alpha|, \mathrm{g} 1=|\mathrm{d} 1|, \mathrm{g} 2=|\mathrm{d} 2|, \mathrm{g} 3=|\mathrm{d} 3| \cdot \mathrm{a} 3, \mathrm{~d} 1, \mathrm{~d} 2, \mathrm{~d} 3$ are the 3rd layer low-frequency signal, the 1st layer high-frequency signal, the 2nd layer high-frequency signal and the 3rd layer high-frequency signal respectively. And $\alpha$ is the normal output value. Assume the mutant point is "i", then from "i" take back 100 points on $\mathrm{f}$, and then calculate the average of the 100 points. This process is called energy analysis. Similarly, carry energy analysis on g1,g2,g3, formulas are as follows:

$$
\begin{aligned}
& \omega 0=\operatorname{mean}[\mathrm{f}(\mathrm{i}) \sim \mathrm{f}(\mathrm{i}+100)] \\
& \omega 1=\operatorname{mean}[\mathrm{f}(\mathrm{i}+100) \sim \mathrm{f}(\mathrm{i}+200)] \\
& \omega 2=\operatorname{mean}[\mathrm{g} 1(\mathrm{i}) \sim \mathrm{g} 1(\mathrm{i}+100)] \\
& \omega 3=\operatorname{mean}[\mathrm{g} 2(\mathrm{i}) \sim \mathrm{g} 2(\mathrm{i}+100)] \\
& \omega 4=\operatorname{mean}[\mathrm{g} 3(\mathrm{i}) \sim \mathrm{g} 3(\mathrm{i}+100)]
\end{aligned}
$$

Values of $\omega 0, \omega 1, \omega 2, \omega 3, \omega 4$ are not completely same to different faults, so we can determine the fault type according to the energy values. The diagnostic characteristics of various faults are shown in Table 1.

Table 1 The diagnostic characteristics of various faults

\begin{tabular}{|l|lll|l|l|l|l|}
\hline Fault Type & $\begin{array}{c}\text { Short-circuit } \\
\text { Fault }\end{array}$ & $\begin{array}{c}\text { Open-circuit } \\
\text { Fault }\end{array}$ & Bias Fault & $\begin{array}{c}\text { Impact } \\
\text { Fault }\end{array}$ & $\begin{array}{c}\text { Periodic } \\
\text { Fault }\end{array}$ & $\begin{array}{l}\text { Random } \\
\text { Fault }\end{array}$ & $\begin{array}{l}\text { Drift } \\
\text { Fault }\end{array}$ \\
\hline Value of $\omega 0$ & $\omega 0=\alpha$ & $\omega 0=\beta$ & $\omega 0 \in(0, \beta)$ & $\omega 0=0$ & $\omega 0=0$ & $\omega 0>0$ & $\omega 0>0$ \\
Value of $\omega 1$ & $\omega 1=\alpha$ & $\omega 1=\beta$ & $\omega 1 \in(0, \beta)$ & $\omega 1=0$ & $\omega 1=0$ & $\omega 1>0$ & $\omega 1>\omega 0$ \\
Value of $\omega 2$ & $\omega 2=0$ & $\omega 2=0$ & $\omega 2=0$ & $\omega 2=0$ & $\omega 2>0$ & $\omega 2>0$ & $\omega 2=0$ \\
Value of $\omega 3$ & $\omega 3=0$ & $\omega 3=0$ & $\omega 3=0$ & $\omega 3=0$ & $\omega 3>0$ & $\omega 3>0$ & $\omega 3=0$ \\
Value of $\omega 4$ & $\omega 4=0$ & $\omega 4=0$ & $\omega 4=0$ & $\omega 4=0$ & $\omega 4>0$ & $\omega 4>0$ & $\omega 4=0$ \\
\hline
\end{tabular}

In Table $1, \alpha$ is the normal sensor output value, $\beta$ is the absolute value of the difference between normal output value and full scale value.

\section{The Experiment}

\subsection{The Experiment Platform and Process.}

The experiment platform is shown in Fig.1, in which a, b, c, d are the Altai company's data acquisition card USB2831, signal generator, voltage/current source, and AD590 temperature sensor system respectively.

The experiment process is provided as follows.

(1) Set up the experiment platform (Fig.1);

(2) At some time during normal work, simulate the sensor's short-circuit fault, drift fault, random fault, and periodic fault respectively (the simulation methods are shown in Table 2), then do data acquisition.

(3) Process the collected data. The rest of the process, please see Section 3.2.

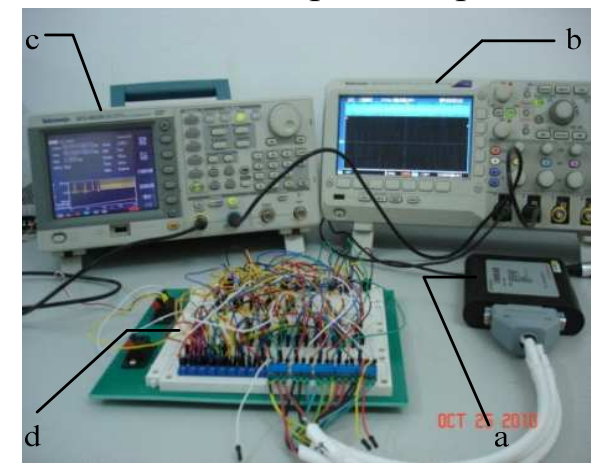

Fig. 1. Experiment platform 
Table 2 The simulation methods of the faults in the experiment

\begin{tabular}{|c|c|c|c|c|}
\hline Fault Type & Short-circuit Fault & Drift Fault & Random Fault & Periodic Fault \\
\hline $\begin{array}{l}\text { Fault } \\
\text { Simulation } \\
\text { Methods }\end{array}$ & $\begin{array}{l}\text { Disconnect the sensor } \\
\text { power, connect the } \\
\text { grounding wire to the } \\
\text { input port of the data } \\
\text { acquisition card. }\end{array}$ & $\begin{array}{l}\text { A ramp signal (the } \\
\text { slope is } 0.001 \text { ) is } \\
\text { added on the original } \\
\text { output signal. }\end{array}$ & $\begin{array}{l}\text { A random signal (mean } \\
0 \text {, variance } 0.1 \text { ) is added } \\
\text { on the original output } \\
\text { signal. }\end{array}$ & $\begin{array}{lr}\text { A sine } & \text { signal } \\
\text { (amplitude 5) is } \\
\text { added on the } \\
\text { original } \\
\text { signal. }\end{array}$ \\
\hline
\end{tabular}

For a clearer description of the experiment process, the Matlab program flow diagram is shown in Fig. 2.

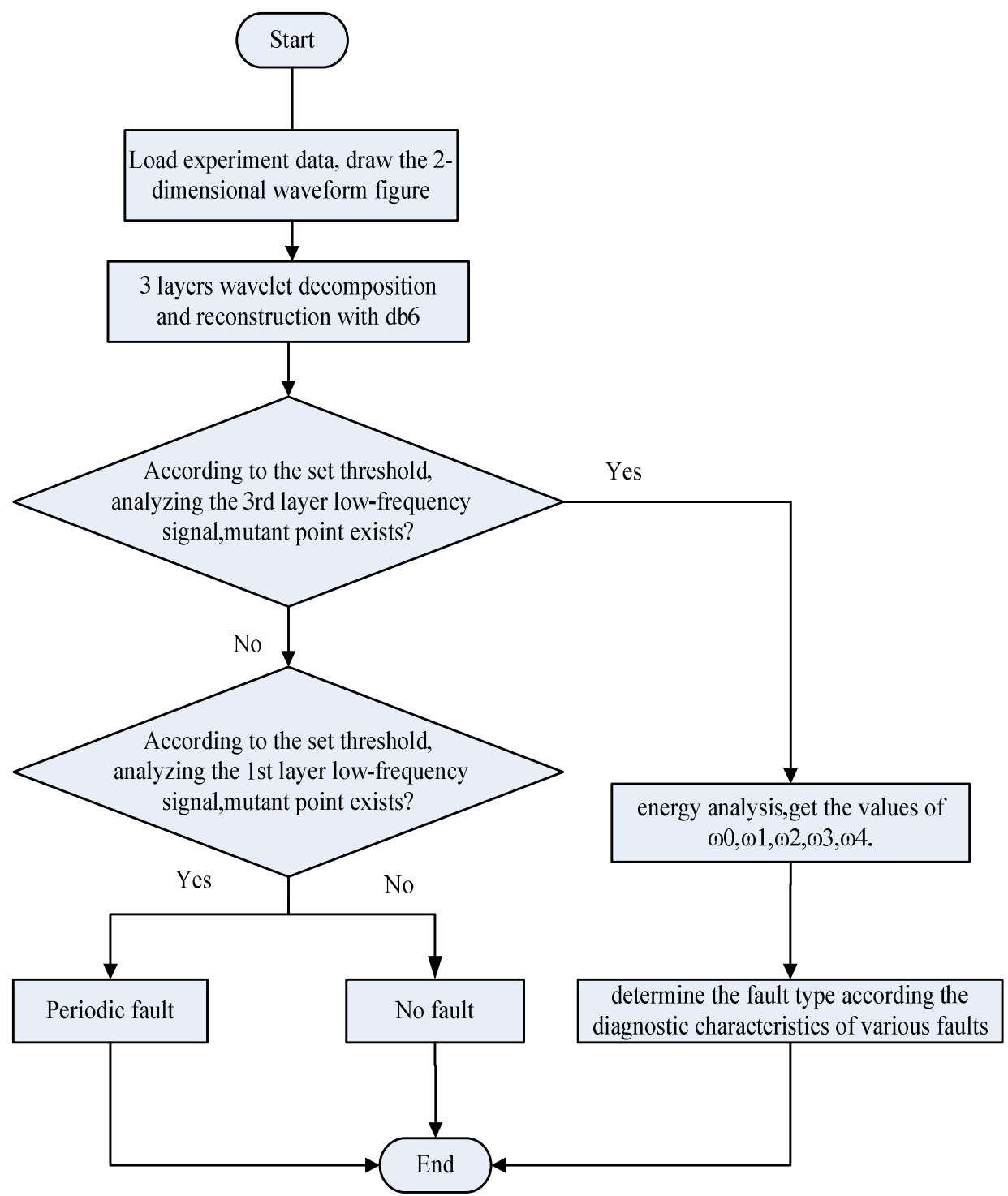

Fig. 2. Program flow diagram

The periodic fault may be no mutant point in the 3rd layer low-frequency signal (the other faults won't) for its period and selected wavelet function. In this experiment, if a sine signal (amplitude 5, period $2 \pi$ ) is added on the original output signal (Fig.3), a mutant point can be found in the 3rd layer low-frequency signal. And the fault type can be judged out according to Table 1.If the period of the sine signal is $\pi / 5$ (Fig.4), we can see there is no mutant point in the 3rd layer low-frequency signal. Then it is necessary to analyze the 1st layer low-frequency signal. 


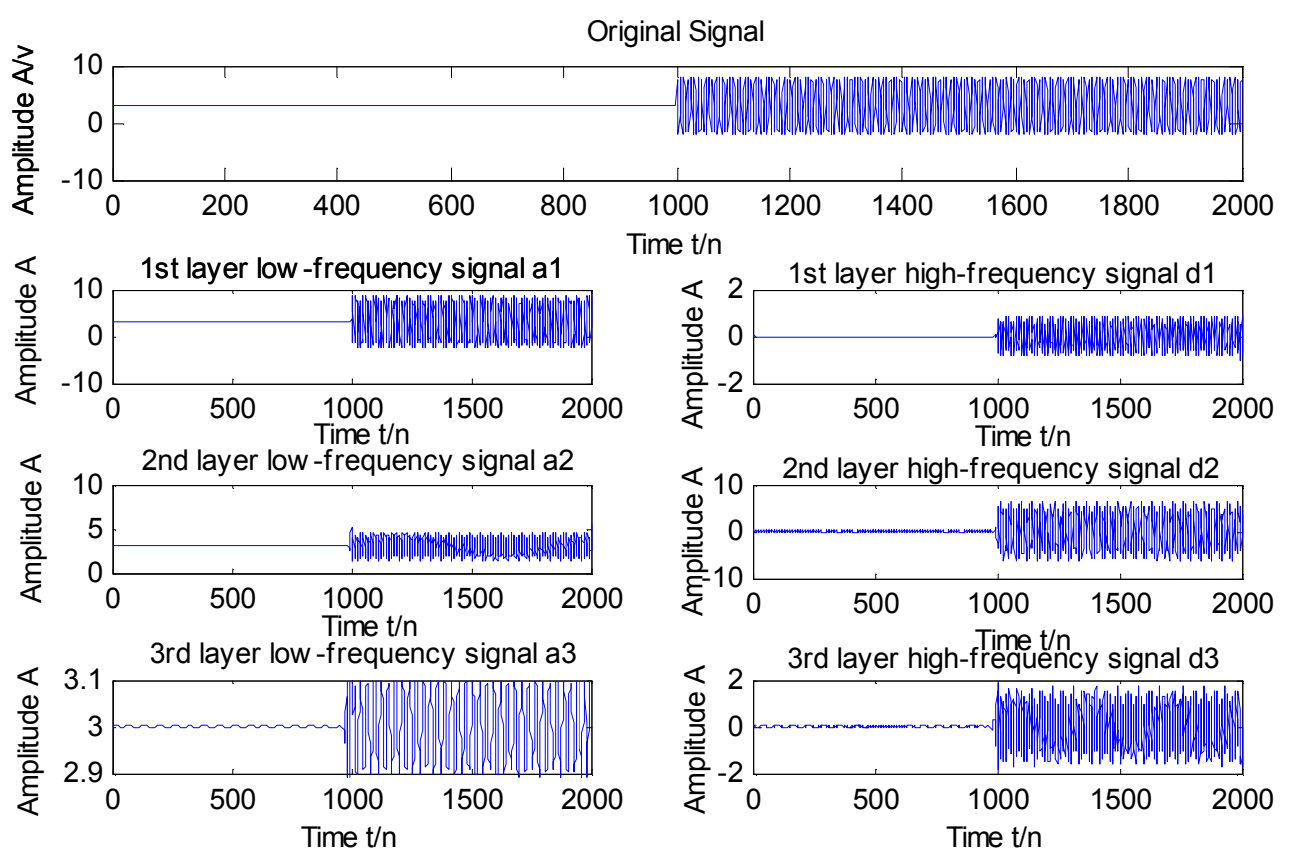

Fig. 3. Original signal and its 3-layer wavelet decomposition result (period $2 \pi$ )
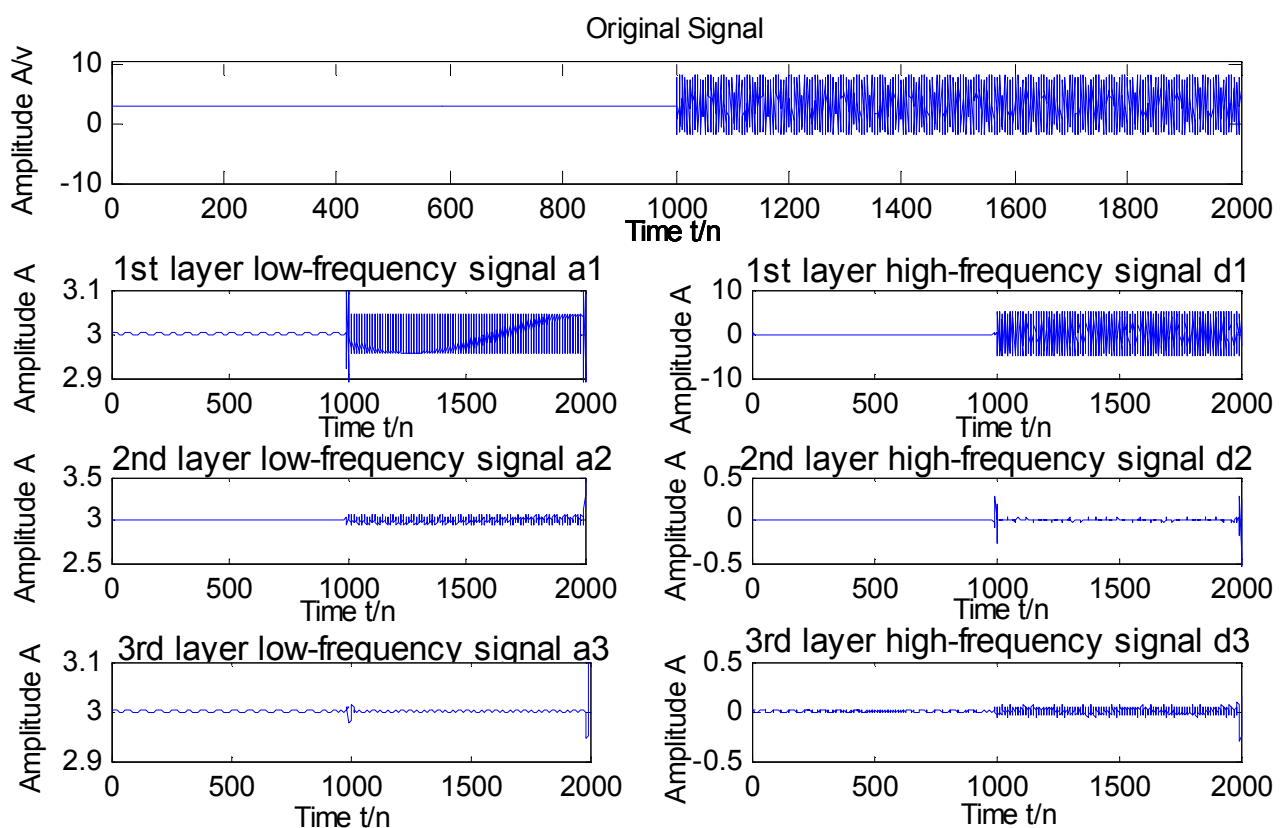

Fig. 4. Original signal and its 3-layer wavelet decomposition result (period $\pi / 5$ )

Please note that in this experiment, the normal output value is $3 \mathrm{v}$, the full scale value is $5 \mathrm{v}$. The thresholds are $2.9 \mathrm{v}$ and $3.1 \mathrm{v}$. The sampling time is $10 \mathrm{~s}$, and the length is 2000 points. Assume that the sensor fault occurs at the $1000^{\text {th }}$ point.

\subsection{Experiment Results .}

The diagnosis results of the above 4 kinds of faults are shown in Table 3.

Table 3. Diagnosis results

\begin{tabular}{|c|c|c|c|c|c|c|}
\hline Mutant Point & $\omega 0$ & $\omega 1$ & $\omega 2$ & $\omega 3$ & $\omega 4$ & Fault Type \\
\hline 996 & $\mathbf{3}$ & $\mathbf{3}$ & $\mathbf{0}$ & $\mathbf{0}$ & $\mathbf{0}$ & Short-circuit fault \\
\hline 1102 & $0.35>\mathbf{0}$ & $0.45>\mathbf{0 . 3 5}>\mathbf{0}$ & $\mathbf{0}$ & $\mathbf{0}$ & $\mathbf{0}$ & Drift fault \\
\hline 1301 & $0.0142>\mathbf{0}$ & $0.0266>0$ & $0.0463>\mathbf{0}$ & $0.0336>\mathbf{0}$ & $0.0277>\mathbf{0}$ & Random fault \\
\hline 981 & $\mathbf{0}$ & $\mathbf{0}$ & $0.4794>\mathbf{0}$ & $2.9609>\mathbf{0}$ & $0.8040>\mathbf{0}$ & Periodic fault \\
\hline
\end{tabular}

It is not difficult to find though there is some deviation in the experiment, it can effectively detect the fault and determine the fault type. 


\section{Conclusion}

Being an effective method for sensor fault detection, wavelet analysis has some advantages that the other methods have not. For example, it does not require the complex equipment and high cost of the hardware redundancy, and it is without the large amount calculation of software redundancy. However, wavelet analysis can only detect fault, it is no help to determine the fault type. Therefore, it is limited in practical application. Energy analysis method based on wavelet transform proposed in this paper, can not only detect the sensor fault, but also diagnose the fault type. And it is closer to practical application. The effectiveness of the method is demonstrated by experiments.

\section{Acknowledgements}

This work is supported by the Advance Manufacturing Basis Fund of Chinese Academy of Sciences (Grant no. Y0F7010701) and the High-grade NC Machine Tools and Basic Manufacturing Equipment (Grant no. 2010ZX04007-011).

\section{References}

[1] Deyst Jr J J, Kanazuwa R M, Pasguenza J P, Sensor Validation: A method to enhance the quality of the man/machine interface in nuclear power stations[J]. IEEE Transaction of Nuclear Science, 1981, NS-28(1): 886-890.

[2] T.H.Gou, J.Nurre, Sensor Failure Detection and Recovery by Neural Networks[J]. IEEE IJCNN, 1991:221-226.

[3] Suyama.K, Fault detection of redundant sensors used in reliable sample-data control systems[J]. Proceedings of the 37th IEEE Conference on Decision and control, Volume: 1, 1998. Page(s): 1161-1164.

[4] Belle, P.Fussel, D.Hecker, Detection and isolation of sensor faults on nonlinear processes based on local linear models[J]. American Control Conference, 1997, Volume: 1, 4-6, June, 1997. Page(s): 468-472.

[5] Sinnasamy R, Naidu, eral, Use of Neural Network for Sensor failure Detection in a Control System[J]. IEEE Control System and Magazine, 1990, (3): 49-55.

[6] Scarl E A, Jamieson J R, Delaune C I, Diagnosis and sensor validation through knowledge of structure and function[J]. IEEE Transaction on System Man and Cybernetics, 1987, SMC-17,(3): 360-368.

[7] Meyer Y, Wavelets and applications. Proceedings of the International Conference. France. Marseille, 1989.

[8] Shine Qian, Time-Frequency and Wavelet Transforms[M]. Prentice Hall PTR, 2001,12.

[9] Reece S, Roberts S, Multi-sensor fault recovery in the presence of known and unknown fault types [J]. Information Fusion,2009.FUSION '09.12th International Conference,2009: 1695-1703. 